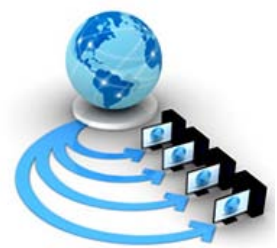

International Journal of Advanced Research in Computer Science

RESEARCH PAPER

\author{
Available Online at www.ijarcs.info
}

\title{
APPLYING FDA IN ADVANCE LEARNING SYSTEM USING STATISTICAL PACKAGE FOR THE SOCIAL SCIENCES
}

\author{
Dr.Jigneshkumar A.Chauhan \\ Assistant Professor \\ Department of Computer Science, Ganpat University \\ Kherva(North Gujarat),India \\ Prof.Jigarkumar D.Patel \\ Assistant Professor \\ Department of Computer Science, Ganpat University \\ Kherva(North Gujarat),India
}

\author{
Dr.Satyen M.Parikh \\ Dean,FCA \\ Department of Computer Science, Ganpat University \\ Kherva(North Gujarat),India \\ Prof.Dhaval K.Raval \\ Assistant Professor \\ Department of Computer Science, Ganpat University \\ Kherva(North Gujarat),India
}

\begin{abstract}
The online web education system opens the new era of the remoteness education, particularly in India, USA, Srilanka. Several online learning course are started in many Universities. Conversely, there is no hands-on facts of pupil's performance to use the web learning innards. In this research paper, we evaluate the value data from the various college of various course, from various Universities of India. All data were collected from the real courses starting from the $1^{\text {st }}, 3^{\text {rd }}$ and $5^{\text {th }}$ semester of year 2012-13, 2013-14, 2014-15.The value data are classified in numerous dimensions, which can show the pupils' behaviour. The study also produces diverse results. This information is very expedient for manipulative the web Learning course.
\end{abstract}

Keywords: Web Learning, Data, KMO, Scree Plot

\section{INTRODUCTION}

Element analysis may be used to Figure idle variables or elements "around watched variables. Over different words, whether those information holds a large number variables, it could be utilization element investigation to decrease the amount for variables. Element investigation bunches variables for comparative aspects together. For element investigation it camwood process An little amount of elements from an expansive number about variables which may be skilled for demonstrating those watched difference in the bigger number about variables. The diminished variables might furthermore make reused to extra dissection.

Here three periods done element analysis: 1st an association grid abides generated all too quite those variables. An association grid abide rectangular gathering of the correspondence coefficients of the variables with one another (Second variables are mined from those association framework constructed on the correspondence coefficients of the variables. 3rd the factors are turned to summon should expand those connection around those variables and sure of the Components.

On the web taking in will be typically said of the exceptional utilization of networked data Furthermore transmission apparatus previously, training and taking in. A numeral of other expressions is likewise utilized to characterize this system for training and taking in. It holds web education, virtual education, scattered education, system Furthermore internet taking in.
Basically, they quite state will informatively forms that devour data What's more correspondences gear should encourage non-concurrent and additionally synchronous training What's more educating occasions. The expression on the web instruction holds a considerable measure extra over web education, virtual education, disseminated education, networked alternately web-based training. The "e" for e-taking in stances for the saying "electronic", web training might fuse every last bit educational occasions that would surrendered crazy Eventually Tom's perusing creatures alternately gatherings working on the web or offline, Also synchronously alternately asynchronously through networked or standalone machines What's more other electronic arrangements.[1].

\section{DESCRIPTIVE STATISTICS}

Here we have divided the input data in three distinct categories of the user bases and they are :(1)Users in the institutes of National importance (2) State-level reputed/ accredited institutes, leading private institutes (3)and Rural institutes

There would three phases clinched alongside element analysis:-

In an association grid may be created for every last one of variables. An association grid may be a rectangular exhibit of the correspondence coefficients of the variables with one another.

Second, variables need aid concentrated starting with the association framework In light of the correspondence coefficients of the variables. 
Third, the variables are turned so as on amplify the association the middle of the variables Also a few of the components.

We collected up to 2200 questionnaires were gathered. The information were assembled as stated by distinctive demographic variables for example, gender, age, also instructive level. Table 1, table 2 demonstrate those sample's diverse spellbinding facts.

Data were collected through an anonymous survey instrument administered to 2200 students of various courses from different institutes or colleges. Respondents for this study consisted of 2080 (1143 Males and 937 Females). The effective sample size was thus 2080 with a response rate of 94.55 percent. Table 3 shows the rotated component matrix with the loadings that are extracted and considered relevant to the constructs.

Here we are interested to investigate the reasons why Elearning System is very less use by the student or people in India rather than the other country. A portion of the variables distinguished likewise continuously persuasive incorporate. Course, Teaching, Time, Result, Understanding, Interest, Desire, Relaxation, Livelyness, Motivation, Teacher Interest, Classmate Interest, Improving Computer Skills, Encouragement and Uninterested.

Starting with this, here it is outlined and questionnaire will request students/peoples' perspective once a five side of the point scale, the place $1=$ determinedly differ what's more $5=$ determinedly agrarian. The effects starting with those questionnaire are indicate on the table The following main those 2080 respondents (cases) would utilized out of 2200 in this example[2].

To begin with yield starting with those dissection may be a table about spellbinding detail for every last one of variables under examination. Typically, the mean, standard deviation. Furthermore amount about respondents $(\mathrm{N})$ who took an interest in the study are provided for. Taking a gander at the mean, you quit offering on that one might infer that respectability about result will be the large portion significant variable that impact scholars or individuals to utilize the e-learning in framework. It need those most noteworthy imply of 4.42 .

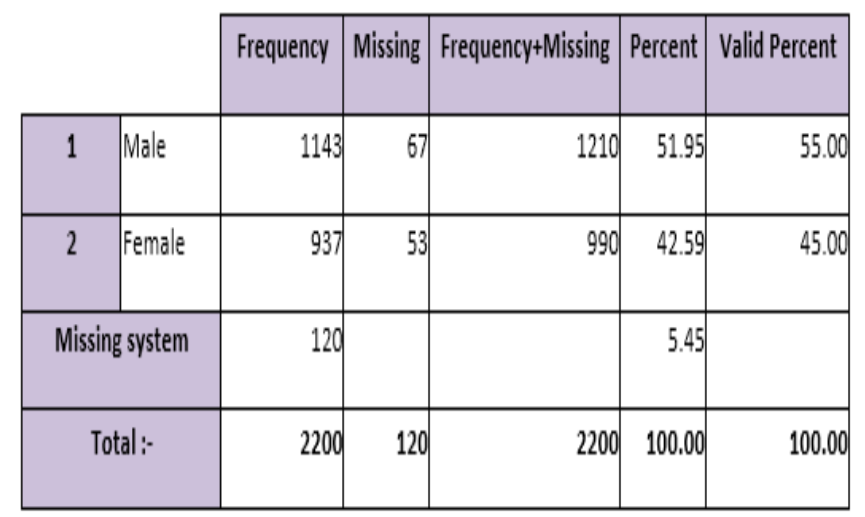

Table 1: Descriptive statistics based on Gender.

The exploratory factor analysis shows that fifteen variables loaded on five distinct factors.

\begin{tabular}{|c|c|c|c|c|c|c|}
\hline & Frequency & Missing & $\begin{array}{c}\begin{array}{c}\text { Prequency } \\
\text { +Missing }\end{array}\end{array}$ & Percent & $\begin{array}{c}\text { Valid } \\
\text { Percent }\end{array}$ \\
\hline 1 & BE-A & 78 & 2 & 80 & 3.55 & 3.64 \\
\hline 2 & BE-III & 75 & 5 & 80 & 3.41 & 3.64 \\
\hline 3 & $\mathrm{BE} \cdot \mathrm{V}$ & 184 & 1 & 185 & 8.36 & 8.41 \\
\hline 4 & Hasc-1 & 82 & 18 & 100 & 3.73 & 4.55 \\
\hline 5 & Mas -1 & 88 & 12 & 100 & 4.00 & 4.55 \\
\hline 6 & $8 \mathrm{BN}-1$ & 166 & a & 166 & 7.55 & 7.55 \\
\hline 7 & $\mathrm{~B}-\mathrm{III}$ & 120 & a & 120 & 5.45 & 5.45 \\
\hline 8 & BCOM-1 & 190 & 0 & 190 & 8.64 & 8.64 \\
\hline 9 & MCOM-1 & 86 & 14 & 100 & 3.91 & 4.55 \\
\hline 10 & ECC-1 & 45 & 20 & 6.5 & 2.05 & 2.95 \\
\hline 11 & BED-1 & 80 & a & 80 & 3.64 & 3.64 \\
\hline 12 & BED-III & 85 & 1.5 & 100 & 3.86 & 4.5 .5 \\
\hline 13 & MCA-1 & 35 & 15 & 50 & 1.59 & 2.27 \\
\hline 14 & $B C A-1$ & 70 & a & 70 & 3.18 & 3.18 \\
\hline 15 & BCAC-III & 130 & a & 130 & 5.91 & 5.91 \\
\hline 16 & $B C A-V$ & 70 & a & 70 & 3.18 & 3.18 \\
\hline 17 & DIP.1 & 70 & a & 70 & 3.18 & 3.18 \\
\hline 18 & ITI & 90 & a & 90 & 4.199 & 4.09 \\
\hline 19 & GNU-I & 46 & a & 46 & 2.09 & 2.09 \\
\hline 20 & GNU-III & 208 & a & 208 & 9.45 & 9.45 \\
\hline 21 & GNU & 82 & 18 & 100 & 3.73 & 4.5 .5 \\
\hline & tal & 2080 & 120 & 2200 & 94.55 & 100 \\
\hline Mis: & 8 system & 120 & & & 5.45 & \\
\hline & tal :- & 2200 & 120 & 2200 & 100.00 & 100.00 \\
\hline
\end{tabular}

\begin{tabular}{|c|c|c|c|}
\hline & Mean & Std. Deviation & Analysis N \\
\hline Course & 4.42 & .503 & 2020 \\
\hline Teaching & 4.28 & .737 & 2020 \\
\hline Time & 2.15 & 1.002 & 2020 \\
\hline Result & 3.97 & .976 & 2020 \\
\hline Understanding & 4.08 & .801 & 2020 \\
\hline Intersesest & 4.22 & .848 & 2020 \\
\hline Desire & 3.80 & 1.053 & 2020 \\
\hline Relaxation & 3.88 & 1.128 & 2020 \\
\hline Livelyness. & 3.76 & .974 & 2020 \\
\hline Motivation & 4.27 & .907 & 2020 \\
\hline Teacher lotersest & 3.65 & .844 & 2020 \\
\hline Classmate Interest & 3.48 & .955 & 2020 \\
\hline Improving Computer Skills & 4.25 & .974 & 2020 \\
\hline Encouragement & 3.83 & 1.127 & 2020 \\
\hline Uninterested & 3.01 & 1.261 & 2020 \\
\hline
\end{tabular}

Table 3: Descriptive Statistics 


\section{KMO TEST}

Those next thing from the yield is the KMO test. Those KMO measures those inspecting sufficiency which ought to further bolstering be more excellent over 0. 5 for an acceptable element investigation to proceed. Taking a gander at the table below, those KMO measure is 0 . 777. Starting with those same table, should be obvious that the Bartlett's test for spherical may be huge. That is, its cohosted likelihood may be under 0.00 .

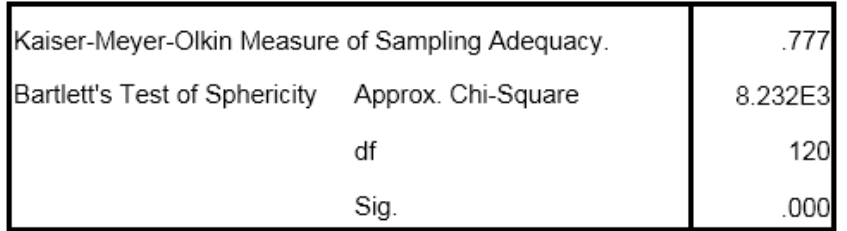

Table 4: KMO Test

\section{COMMUNALITIES}

Those next thing from the yield will be a table of communalities which reveals to upon what amount of the difference in the variables need been accounted to toward the concentrated elements. For example again $87.5 \%$ of the difference done showing may be accounted to same time 40. $9 \%$ of the difference on cohort enthusiasm is accounted [3].

\section{Communalities}

\begin{tabular}{|l|r|r|}
\hline & \multicolumn{1}{|c|}{ Initial } & Extraction \\
\hline Userno & 1.000 & .682 \\
Course & 1.000 & .515 \\
Teaching & 1.000 & .875 \\
Time & 1.000 & .621 \\
Result & 1.000 & .493 \\
Understanding & 1.000 & .621 \\
Intersest & 1.000 & .663 \\
Desire & 1.000 & .607 \\
Relaxation & 1.000 & .575 \\
Livelyness & 1.000 & .512 \\
Motivation & 1.000 & .412 \\
Teacher Intersest & 1.000 & .511 \\
Classmate Interest & 1.000 & .409 \\
Improving Computer Skills & 1.000 & .598 \\
Encouragement & 1.000 & .603 \\
Uninterested & 1.000 & .775 \\
\hline
\end{tabular}

Extraction Method: Principal Component Analysis.

Table 5: Communalities

\section{SCREE PLOT}

The scree plot is a chart of the eigenvalues against every last one of elements. The chart will be advantageous for figuring out know what number of variables with hold. The side of the point for premium is the place the bend begins should straighten. It could make seen that those bend starts on straighten the middle of variables 3 and 4 . Note Additionally that element 5 need a eigenvalue of short of what 1 , something like that best three factors bring been held.

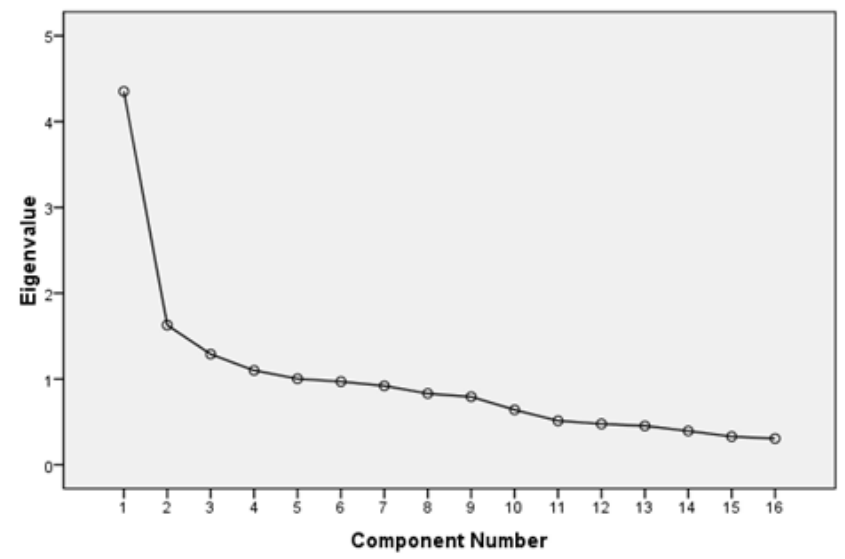

Figure 1: Scree Plot

\section{DISCUSSION AND FINDINGS}

Those brings about table 2(Descriptive detail In light of Education) which predicted that Indian scholars will demonstrate negative attitudes at online learning in because of their universal see from claiming training. From those comes about we might infer that Indian learners need positive position attitudes towards the utilization from claiming innovation to instruction. Looking at those effect from claiming distinctive variables for example, sex What's more instructive level on the attitudes at e-taking in will be the second target for this ponder. Out comes about upheld table 1(Descriptive facts In view of Gender) which predicted no huge contrasts previously, attitudes towards online learning in. In light of those respondents' sex status. There might have been not backed as there might have been critical distinction in attitudes towards e-taking in In view of the student's instructive level.

In the part grid table it indicates the loading of the fifteen variables on the five Components concentrated. Those higher those supreme esteem of the loading, the additional the variable contributes of the variable. Those hole on the table re-presentable loading that are under 0.5 , this makes perusing those table less demanding. We smothered the greater part loading under 0.5 .

In the downright difference demonstrated it demonstrates every last one of components extractable from the dissection alongside their eigen values, those percent about difference attributable will each factor, and the combined difference of the figure and the past variables. Notice that those 1st element accounts for $27.201 \%$ of the variance, those second 10. $176 \%$, those 3rd $8.059 \%$, those 4th $6.873 \%$ and the 5th 6. 266. Every last one of remaining elements need aid not noteworthy. 


\section{REFERENCES}

[1] Jigneshkumar A. Chauhan, Dr.N.J.Patel and Dr.V.R.Rathod,"Factor Data Analysis of ELearning with the SPSS 16.0 in IT Education",IJAIR,vol.2,Jan 2013.
[2] Jigneshkumar A.Chauhan and Dr.V.R.Rathod,"To study of Learning Model, Trends and Technology of E-Learning”, Conference p.258-262,2011

[3] Jigneshkumar A.Chauhan and Dr.V.R.Rathod,"ELearning Models and it's media",AES Journals p.50-53,Sept 2011 